Post-Print Version of:

Reuland, Y., Lestuzzi, P. and Smith, I.F.C., 2019. An engineering approach to model-class selection for measurement-supported post-earthquake

assessment. Engineering Structures, 197, 109408

doi.org/10.1016/j.engstruct.2019.109408

\title{
An engineering approach to a-priori model-class selection for measurement-supported post-earthquake assessment.
}

\author{
Yves Reuland ${ }^{\mathrm{a}, *}$, Pierino Lestuzzi ${ }^{\mathrm{a}}$, Ian F.C. Smith ${ }^{\mathrm{a}}$ \\ ${ }^{a}$ Applied Computing and Mechanics Laboratory (IMAC), School of Architecture, Civil and \\ Environmental Engineering (ENAC), Swiss Federal Institute of Technology (EPFL), \\ Lausanne, Switzerland
}

\begin{abstract}
Structural identification of existing structures is a subject of increasing interest in the civil-engineering community because of its potential to use measurement data to enhance asset-management decision making. An important structuralidentification application is residual-capacity assessment of earthquake-damaged structures. Known to be potentially slow and subjective, current assessment practices rely mostly on expert-conducted visual inspection. Structural-identification techniques can help overcome these shortcomings through improving estimates of residual capacity. Physics-based models are needed to predict structural behavior under future loading. For earthquake-engineering simulations, a large variety of prediction models and techniques exists. While engineers often prefer simplified behavior models for assessment, data-interpretation applications usually involve detailed model classes. Neither choice is appropriate for all situations. To improve upon current practice, this paper contains a proposal for a more rational a-priori model-class selection, based on availability of several sources of information. While, knowledge of the earthquake signal is identified as a main criterion to select model classes and analysis tools, the number of measured frequencies that could be inferred from measurements and the amount of building and material information are other criteria that help select an appropriate model
\end{abstract}

\footnotetext{
${ }^{*}$ Corresponding author

Email address: yves.reuland@epfl.ch (Yves Reuland)
} 
class prior to behavior simulations. Model-class selection criteria are described and illustrated using two cases. Displacement-demand predictions are reduced by up to $91 \%$ using structural identification techniques and are validated for all tested model classes by observed behavior under aftershocks. Applicability of this model-class selection is most attractive for post-earthquake assessment of residual capacity (not damage detection) where there is a reduced availability of measurement data, such as when there are no continuous monitoring data. This strategy provides useful and fast support to engineers for key decisions related to asset management and structural resilience.

Keywords: Model-class selection, Post-seismic capacity assessment, Model fidelity, Seismic vulnerability of existing buildings, Model-based measurement interpretation, Error-domain model falsification

\section{Introduction}

Earthquakes present rare loading events with levels of shaking that threaten structural integrity of buildings. Especially in regions with low-to-moderate seismic hazard, the shortcomings of early design codes and slow building-replacement 5 rates result in many vulnerable buildings. As modern design practices focus on life safety (rather than on unsustainable design targets for structural integrity during earthquake events that are characterized by high return periods), earthquakes will continue to deteriorate structures and thus, post-earthquake assessments will continue to be important tasks. Also, design approaches rarely include deterioration due to multiple earthquake occurrences [1, which further increases the need for good model-based predictions of the behavior of deteriorated buildings. Current practice for post-earthquake assessments heavily relies on visual inspection [2, 3. In addition to being subjective [4, 5, and inappropriate for predictions [6], the slowness of visual inspection [7, 8] is incompatible with the need for rapid decision-making that is due to the immediate threat of subsequent earthquake events and delayed collapses. Structural-identification techniques have the potential to reduce the subjectivity of post-earthquake assessment and 
to reduce the time between an earthquake and a decision regarding safety for occupancy of deteriorated buildings 9. Hence, structural resilience with respect to seismic hazard can be improved.

Jalayer et al. 10 proposed including the probability of aftershocks (based on a non-homogenous Poisson model) to support post-earthquake decision making in L'Aquila (Italy). Goulet et al. [11] proposed a Bayesian probability-updating scheme for vulnerability curves in order to reduce the number of buildings to be inspected without losing information related to the damage on a city scale. Hernandez and May [12] used energy-based interpretation of measurements taken during earthquakes to estimate structural damage. Naeim et al. [13, 14] proposed a methodology to estimate the extent of damage in each building floor in the immediate aftermath of an earthquake based on fragility functions and so a dense network of sensors that permanently measure during the earthquake. Sensor-based building monitoring that meets building owners' need for rapid decision making after earthquakes has been proposed [15. However, model-based measurement-interpretation strategies for behavior prediction during subsequent earthquakes are scarce.

Equipping strategic buildings with sensors could be a first step to reducing uncertainty in a post-earthquake environment [16. In addition, updated vulnerability assessments for buildings characterized by a given damage state after a main-shock have been proposed [17, 18, 19]. However, few studies incorporate measurement interpretation to update vulnerability curves after the main shock.

40 In addition, uncertainties are generally limited to ground-motion parameters, not behavior-modelling uncertainties.

Structural engineers reason using approximate and safe behavior models to simulate complex physical phenomena in order to design and evaluate structures. Vulnerability assessment often involves analyzing large building populations 45 and thus, pre-seismic-assessment tasks commonly involve simplified behavior models (such as proposed by Risk-UE in Europe [20, 21]). However, datainterpretation applications often involve refined three-dimensional finite-element models $22,23,24,25,26$. Nonlinear hysteretic models, which are needed to 
perform behavior prognosis under future earthquake loading, add a substantial number of parameters to identify. Also, depending on the purpose of data interpretation (such as residual-capacity assessment, damage localization and design of repair measures) even more detailed models may be required. Both modeling and final-use aspects need to be taken into account when selecting an appropriate model class. In this paper, model classes are defined with respect to the scale of details of the model, also referred to as model fidelity (i.e. the extent to which a physics-based model reproduces physical phenomena that define structural behavior). Simplified models should not be excluded from the start 27. Therefore, in this paper, criteria for a-priori (before any simulation is performed) model-class selections are proposed. It is impossible to formulate model-class-selection criteria that have universal validity. A-priori model-classselection criteria are formulated for the scope of model-based measurement interpretation for post-seismic residual-capacity assessment of buildings not equipped with permanent monitoring.

In this paper, structural identification of damaged buildings after a mainshock is performed using error-domain model falsification (EDMF). EDMF is based upon the principle of scientific discovery [28]: measurements are most useful when they are used to falsify models. EDMF uses thresholds to discard model-parameter instances that are incompatible with observed behavior, rather than optimizing single models [29]. Relying on thresholds to falsify model instances is equivalent to using uniform probability distributions between bounds. This makes EDMF more robust with respect to unknown and changing uncertainty correlations between measured quantities as no correlation values are needed [30. EDMF has been shown in previous work to be accurate when predictions are extrapolations [31, 32, 33. Extrapolation is necessary to predict 75 structural behavior under earthquake loading with model instances that are updated using post-earthquake data, as loading conditions differ notably from measurement conditions. Well-known model-identification techniques, such as residual minimization and traditional applications of Bayesian model updating (when uncorrelated zero-mean Gaussian likelihood functions are assumed), are 

uncertainties [34], and this undermines accuracy of extrapolation predictions [31, 32]. Recently, compatibility has been established between EDMF and Bayesian updating techniques when they adopt uniform likelihood functions [35, 33].

85 cornerstone of typical selection criteria was the principle of parsimony that favours explanations with minimal assumptions for observed behavior. Translated to structural identification, applications of the principle of parsimony resulted in selecting model classes with a low number of parameters [36. In this way, Bayesian model updating, model-class selection through calculating posterior evidence was proposed to identify optimal model classes [37, 38]. Also, posterior model averaging (based on various model classes) was proposed to increase prediction robustness [39, 40]. Pasquier and Smith [31] showed that despite posterior model averaging in Bayesian model-updating applications, erroneous prediction distributions have been obtained, when un-correlated zero-mean Gaussian likelihood functions are used. Most model-class selection approaches were based on a-posteriori selection of model classes (after running simulations for all the model classes and performing model updating). A-priori selection of model classes that were compatible with engineering reasoning and that could be applied with observations following an earthquake were not proposed. In addition, many proposed model-selection criteria were based on feature selection, which means selecting an optimal number and combination of parameters to identify. Van Buren et al. 41] compared model classes using robustness and fidelity criteria taking into account modelling uncertainty. Few other proposals proposed model-class selection in terms of model fidelity.

In this paper, criteria for a-priori selection of an appropriate model class are presented. These selection criteria allow engineers to choose, prior to any simulation, the most promising model class and type of analysis in order to assess, through model-based data interpretation, the residual load-bearing be- 
havior of a building after an earthquake. The assumed context of this work is post-earthquake assessment of buildings with natural frequencies (derived from post-seismic ambient vibration measurements) and visual damage inspection. Continuous monitoring is assumed to be unavailable and thus, information is limited to visual inspection and natural frequencies obtained from measurements after the mainshock. The paper starts with a description of the theoretical background (EDMF, existing model classes and seismic prediction methods) in section 2 then model-class selection based on existing information is presented (section 3) and subsequently applied to two case studies (section 4).

\section{Background}

Details of the data-interpretation methodology, existing simulation models and types of analyses for seismic-behavior predictions are discussed in this section in order to provide supporting information for the proposed model-selection criteria (see section 3).

\subsection{Model-based measurement interpretation using error-domain model-falsification} $(E D M F)$

In this paper, EDMF is used to compare model predictions with measured behavior. Goulet et al. 42 have formalized the principle of model falsification into a probabilistic strategy by introducing falsification thresholds that are derived from estimated (modelling and measurement) uncertainty sources. Given the complexity and uniqueness of engineering structures and changes in uncertainty sources (such as boundary conditions) with atmospheric conditions, uncertainties from multiple sources are estimated and combined. Modelling uncertainties, $U_{g}$, and measurement uncertainties, $U_{\hat{y}}$ are combined in order to obtain a combined 135 joint probability density function, $f_{U_{c}}\left(U_{c}\right) \sim U_{\hat{y}}-U_{g}$. In application to engineering structures, modelling uncertainties have been shown to have a higher variance than measurement uncertainties [43] and to be systematically biased [29]. 
Based on the combined uncertainty distribution, $f_{U_{c}}\left(U_{c}\right)$, lower and upper shortest interval of $f_{U_{c}}\left(U_{c}\right)$ that corresponds to a target probability $\phi_{d}$ as shown in Eq. 1. To account for the simultaneous comparisons of $n_{m}$ residuals (between measured quantities and the corresponding model predictions) with threshold values, the Šidák correction for multiple-hypotheses testing [44] is usedin Eq. 145 achieved.

$$
\forall i \in\left\{1,2, \ldots, n_{m}\right\}: \phi_{d}^{1 / n_{m}}=\int_{T_{\text {low }, i}}^{T_{\text {high }, i}} f_{U_{c, i}}\left(U_{c, i}\right) d U_{c}
$$

Residuals between measurements and model predictions are compared to the threshold values and discarded if for any measured quantity $i$ (out of $n_{m}$ measured values) the residual, $g_{i}(\theta)-\hat{y}_{i}$, does not match equation 2, Parametercombination instances that are not falsified using equation 2 are retained as candidate models and are assumed to be equally likely.

$$
\forall i \in\left\{1,2, \ldots, n_{m}\right\}: T_{\text {low }, i} \leq g_{i}(\theta)-\hat{y}_{i} \leq T_{\text {high }, i}
$$

Rectangular regions of acceptance of residuals between model predictions and measurements provide candidate models that are robust with respect to unknown and changing correlations between residuals related to multiple measured quantities [45, 31].

\subsection{Model-class types for seismic analysis}

Earthquake-engineering applications provide a large range of model classes that are characterized by a changing fidelity to real structural behavior. Nonlinear hysteretic single-degree-of-freedom (SDOF) representations are simplified models that predict dynamic behavior based on the modal mass and the generalized stiffness related to the first mode. Hysteretic nonlinear behavior is introduced in SDOF models by defining a yield point and, depending on the sophistication of the chosen hysteretic model, post-yield stiffness as well as parameters governing 
unloading and reloading. A refinement of SDOF representations is obtained by representing each floor with a separate degree of freedom in a multipledegree-of-freedom (MDOF) representation. In such models, plasticity (hysteretic nonlinearity) is often lumped into nonlinear springs, governed by the same parameters than SDOF models.

Equivalent-frame models represent all structural elements (walls, columns) as frame elements. Equivalent frame models have shown satisfactory results when pushover curves are simulated [46, 47, 48. However, natural-frequency predictions are often biased. Depending on the implementation of equivalentframe models, plasticity can be lumped into characteristic nodes or smeared throughout frame elements.

Although computationally burdensome, complex three-dimensional models are also available. While finite-element models often fail to produce accurate predictions involving highly nonlinear displacements (such as encountered when estimating ultimate displacement values), the applied element method (AEM) captures the building behavior from the elastic range to failure, including large material and geometric nonlinearities. AEM models are used in this paper as examples of high-fidelity model classes. AEM involves dividing structural components into elements that are connected with springs at element contact points. Pairs of normal and shear springs localize stresses, strains and deformations [49. Nonlinear behavior is assumed to be similar to concrete-type behavior models [50]. Nonlinear springs are able to capture joint de-bonding, shear sliding, direct tension and partial connectivity between elements. However, shear-compression failure due to high axial loads is not taken into consideration. AEM has been shown to predict post-yield structural behavior of reinforced-concrete and masonry structures that are defined by a large range of potential failure modes [51, 52, 53, 54, 55].

In order to perform post-earthquake identification, structural models need to capture the drop in natural frequencies that results from damage. For models that rely on smeared plasticity, predicting a link between maximum displacement and a reduction of natural frequencies is complex. If plasticity is lumped into 

straightforward.

In this paper, a simplified approach towards stiffness reductions is applied for SDOF models and nonlinear springs. The secant stiffness to the maximum displacement is used, as shown in Figure 1. As structures recover stiffness at lower amplitude vibrations after earthquakes(as is the case for frequencies derived from measurements under ambient conditions), the secant stiffness, $k_{s e c}$, results in a lower limit to the real damaged stiffness, $k_{p e q}$. Michel et al. [56] quantified the frequency drop between ambient vibrations and large-cycle vibrations to be $33 \%$ for un-reinforced masonry structures. Although this value involves large uncertainties (a scatter of $\pm 9 \%$ has been found for calcium-silicate and $\pm 6 \%$ for clay bricks in the case of low-rise brick masonry buildings), this approach will be followed to derive the stiffness under ambient vibrations from the secant stiffness (see Eq. 3).

$$
k_{p e q}=\frac{1}{0.66^{2}} \cdot k_{s e c} \approx 2.3 \cdot k_{\text {sec }}
$$

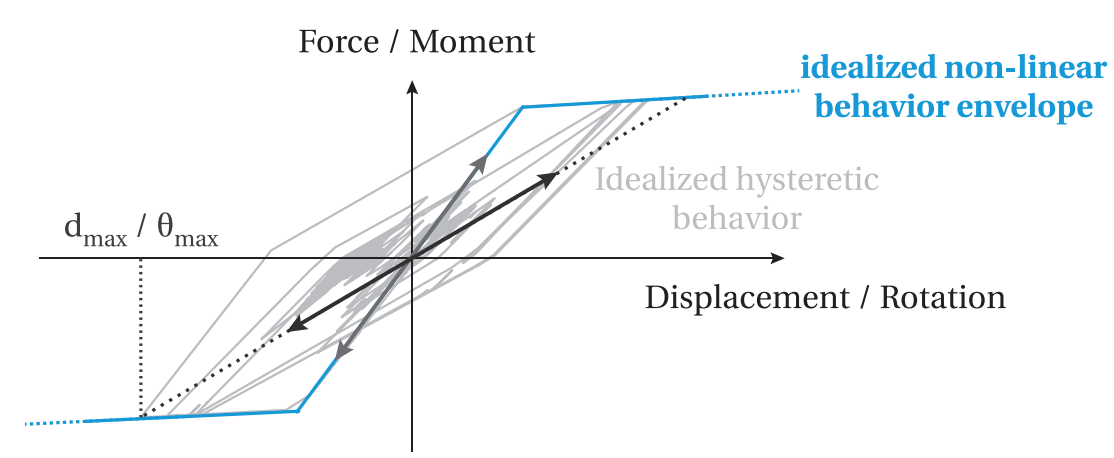

\section{$\longleftrightarrow$ Initial stiffness $\longleftrightarrow$ Damaged stiffness (lower bound)}

Figure 1: Methodology for stiffness updating of hysteretic behavior models (such as lumpedplasticity hysteretic spring models or SDOF hysteretic models). The secant stiffness to the maximum (absolute) displacement is a lower bound for damaged stiffness. 


\subsection{Seismic-analysis approaches: static and dynamic nonlinear predictions}

210 dynamic (or time-history) analyses are most powerful . However, such analyses are computationally expensive, especially in multiple-model approaches such as EDMF (see Section 2.1). Also, setting appropriate loading steps and controlling convergence are challenges related to dynamic nonlinear simulations that are not within the scope of this paper.

Static nonlinear approaches are computationally less demanding than dynamic nonlinear analyses [58, 59. Such nonlinear static analyses have also been applied to mixed masonry and reinforced-concrete structures [60]. Examples of methods to predict the displacement demand resulting from given response spectra using 62, 63, which includes the equal-displacement rule [64, 58. Although limitations of the N2 method have been shown in the past [65, 66], it is used in this paper. Pushover-based vulnerability predictions involve the assumption of inplane-collapse mechanisms. By enforcing a certain load distribution (often 225 a distribution that is similar to the mode shape of the fundamental mode), the collapse mechanism is often limited to in-plane load-bearing, which is not realistic for some building types. Recently, adaptive pushover techniques have been proposed to overcome some of these limitations [67, 68. In this paper, classic pushover curves are used and the resulting extra uncertainty is taken into

\subsection{Model-based data interpretation in post-earthquake applications}

As structural identification in a post-earthquake scenario is proposed, initial (pre-earthquake) modal properties are likely to be unavailable. To overcome this limitation, the outcome of visual inspection - taking the form of a damage grade (DG), defined by the European Macroseismic Scale (EMS98) 69] - is used as an additional measurement source. Based on existing work [70, 71], observed DGs can be transformed to displacement values through the use of limit-state mechanical properties of the structure: yield displacement $d_{y}$ and 
ultimate displacement $d_{u l t}$. The quantification of an observed DG results in model instances that are not compatible with observations, as described in 72 .

When static nonlinear predictions are used an approximate model falsification scheme can be employed. Based on the measured post-earthquake frequency and the combined uncertainty distribution, ranges of compatible structural displacements (such as top displacement or first-story drift) are obtained. In a similar way, an interval of displacement-demand values that are compatible with visually observed DGs can be derived. Candidate parameter combinations verify the condition of a non-null intersection subset between the displacement demand intervals defined by measured post-earthquake frequency and those defined by observed DGs [73]. Candidate models obtained using this approximate, static nonlinear approach require no information regarding earthquake ground motion or initial building states.

To underline the importance of knowledge of the earthquake accelerogram, the parameters of a theoretical SDOF model are updated using the post-seismic

Artificial model uncertainties arises from changing damping, stiffness updating (see Eq. 1) and the hysteretic rule (modified Takeda rule 74 for simulated measurements and elastic-plastic rule for model predictions). In addition, a random instance of measurement uncertainty is added.

265 If the accelerogram of the earthquake is known, identification involving dynamic simulations (88.4\% of the initial model population is falsified) outperforms static simulations (76.4\%). However, in absence of knowledge regarding the earthquake signal (15 historic accelerograms with peak ground acceleration (PGA) between $3 \mathrm{~ms}^{-2}$ and $8 \mathrm{~ms}^{-2}$ are randomly selected, while the true earth- 
quake signal has a PGA of $5 \mathrm{~ms}^{-2}$ ), the performance of model identification using dynamic simulations drops (59.4\% falsified model instances). Figure 2 shows the identification results for two parameters, initial frequency and yield displacement, resulting from the three identification scenarios. Static simulations provide intermediate results between dynamic simulations with and without signal knowledge. Therefore, in absence of signal knowledge and when only post-earthquake measurements are available, static simulations are used for structural identification.

(a) Dynamic simulations (with signal knowledge)

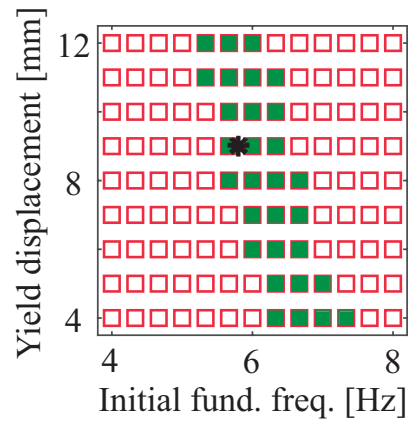

(b) Dynamic simulations (no signal knowledge)

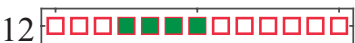

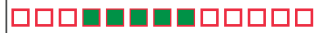
ㅁㅁㅁㅁㅁㅁ

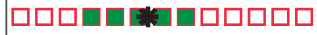

8 ㅁㅁㅁㅁㅁㅁㅁำ ㅁㅁㅁㅁㅁㅁ ㅁㅁㅁㅁㅁㅁ․ ㅁㅁㅁㅁㅁㅁ

4 맘ㅁㅁㅁㅁㅏ. $\begin{array}{lll}4 & 6 & 8\end{array}$ Initial fund. freq. [Hz] (c) Static simulations

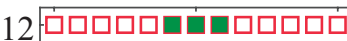

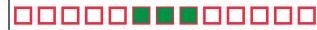
ㅁㅁㅁㅁㅁㅁ

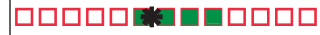

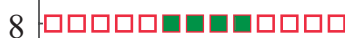

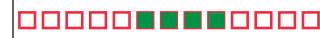

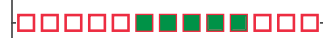

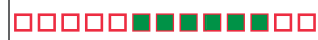

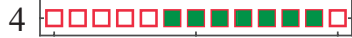
46 Initial fund. freq. [Hz]

- Candidate model instances $\quad \square$ Falsified model instances $\quad *$ True values

Figure 2: Comparison between structural identification results (using simulated measurements) that are obtained using dynamic simulations with earthquake signal knowledge (a) and without earthquake signal knowledge (b) as well as with static nonlinear simulations (c). For static nonlinear simulations (c) no signal knowledge is required and thus, identification results are between dynamic simulations with and without signal knowledge in terms of falsification performance. 


\section{Civil-engineering-compatible criteria for model-class selection in a post-seismic context}

280 dimensional models. However, in this paper, model classes with changing sophistication (level of detail at which the model represents material behaviour and geometrical features of the structure) are compared and an a-priori selection scheme is proposed. By changing sophistication, from highly simplified to highly

complex behavior models, simulation time, number of parameters, quantity of comparisons between model and measurements, as well as level of uncertainties change, as schematically reported in Figure 3 . With increasing sophistication, the number of degrees of freedom increases as well. High sophistication involves a high number of degrees of freedom and this results in expensive computation time (see first graph in Figure 3). In addition to a growing number of degrees of freedom, models with higher fidelity also involve more parameters (of potentially unknown value), as a more precise description of building geometry and material properties is necessary. For instance, global behavior simulations using a SDOF model involves four to seven parameters, while a detailed three-dimensional model with material non-linearity can reach more than 50 parameters in case of mixed buildings. This schematic trend of a growing number of parameters with higher model sophistication is reported in the second graph of Figure 3.

A positive outcome of a better geometrical representation of the structure, with more degrees of freedom, is related to multiple comparisons between measurements and model predictions (for instance higher natural frequencies and their respective mode shapes are simulated and can be compared with measurements, if available). Simplified model classes are generally defined by a very limited number of degrees of freedom and allow a maximum of three comparisons: initial fundamental frequency, post-earthquake fundamental frequency and observed DG. Although the Sidak correction (see Section 2.1 and Equation 11 in EDMF helps account for the effect of small numbers of measurements, three measured quantities may be insufficient for efficient structural identification, 
especially since in most applications (in regions with low-to-moderate seismicity) the initial fundamental frequency is likely to be unavailable. Although too many measurements may lead to over-fitting the data, the amount of measurements in a post-seismic context remains small and thus, the risk of over-fitting is low.

A more sophisticated model is intended to increase fidelity of the model to reality and thus, reduces the modelling uncertainty. However, an increase of parameters (resulting from increasing sophistication) increases the risk of un-identifiability of unknown parameter values (see fifth graph in Figure 3). Two reasons can lead to un-identifiability: either large amounts of parameters may lead to compensations of effects on structural behavior or treating less important parameters as secondary parameters (not intended to be identified) increases uncertainty. Thus, when the number of parameters grows above a certain value, uncertainty increases despite higher model fidelity, as indicated in the forth graph of Figure 3.Ultimately too sophisticated models can hinder successful application of model-based data interpretation.

Ideally, model-class selection should optimize the parameter identifiability. However, based on the measurement data that is available and the information regarding the earthquake signal and the building geometry and material, the actual position of the curves and the ' $X$ ' in figure 3 changes. Therefore, the influence of these factors (amount of measurement data, precision of mainshock-signal information, level of detail of building and material information) on model-class selection needs to be taken into account.

330

Even for physics-based models that involve a high number of parameters, sensitivity analyses (or more elaborated feature-selection techniques) are usually employed to keep a low number of parameters that are to be identified. In addition, traditional applications of EDMF involve grid sampling and thus, the number of model simulations that need to be performed grows exponentially with the number of parameters. In such a scenario, identifying more than five parameters is computationally expensive. As a result, increasing numbers of parameters lead to a growing number of secondary parameters, which are not identified and add to the combined uncertainty. Therefore, the reduction in 


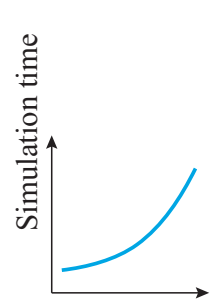

Sophistication

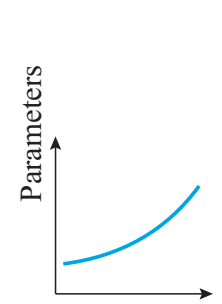

Sophistication

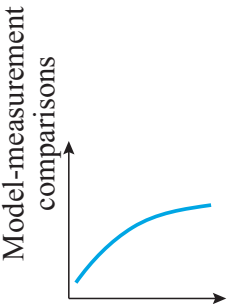

Sophistication

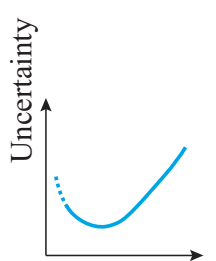

Sophistication

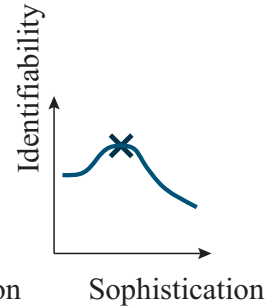

Figure 3: Schematic representation of the influence of model sophistication (here as function of the number of degrees of freedom) on computation time, number of parameters, number of predictions that can be compared with measurements and parameter identifiability. Determination of the position of ' $\mathrm{x}$ ' is not obvious and it varies with the amount of information in measured data. Schematic trends are confirmed by the firstfisrt case study, as shown in Figure 10

uncertainty that can be obtained by increasing model fidelity is often counter-

balanced by increasing parameter uncertainty (see fourth graph in Figure 3).

In applications that involve predictions, two competing sources of uncertainty can be related to increasing model fidelity. While higher model fidelity may reduce modelling uncertainty (less simplifications are made and predictions may be more precise) the need for more parameters to adequately describe nonlinear non-identifiable parameters and each material, such as bricks, mortar, concrete, reinforcement steel, is represented individually) that can only be partially reduced with structural identification.

Predictions that are made to estimate residual capacity involve either simulating multiple time-series with changing intensities or rely on static nonlinear pushover curves to predict displacement demands (as discussed in Section 2.3. While simple models such as SDOF or MDOF representations allow multiple dynamic nonlinear simulation runs, complex models with a high number of degrees of freedom are usually restricted to pushover-curve predictions.

A drawback of simplified models is the fact that they capture a limited number 
of failure mechanisms. For instance out-of-plane mechanisms and instabilities are not captured by lumped-mass models. In a similar way, the domain of applicability of pushover curves is limited to cases where out-of-plane mechanisms are excluded and where there are rigid floors. Thus, observations from visual inspection should be included in the process of model-class-fidelity selection. Model-based post-earthquake assessment thereby complements visual inspection, replacing expert-conducted visual inspection is not intended. Another limitation of simplified lumped-mass models is related to the unidirectional analysis. Usually, for simplified models the analyses is split into the two main building directions. Hence, torsional effects are neglected along with increased vulnerability due to interactions between building directions. However, even with complex models, earthquake actions are usually applied to the main directions of the building as combining several possible two-dimensional earthquake signals is computationally burdensome.

A summary of model classes that are characterized by increasing model fidelity - from SDOF representations to three-dimensional representations - is provided in Figure 4. Although the number of comparisons between model predictions and measurements increases, calculation time varies in an exponential manner from simplified to high-fidelity models.

375 The considerations that guide a-priori selection of a model class depends on engineering judgment rather than on a simple application of the principle of parsimony. A guide to decision making regarding an appropriate model class is provided in Figure 5. The information sources that are identified to influence the selection of model-class fidelity are: the number of modes that are measured; ground-motion knowledge (such as amplitude and frequency content); and building information that is available (such as material types and construction drawings).

The number of modes that can be derived from ambient-vibration measurements is governed by the number of sensors used and the structural system. ${ }_{385}$ Also, in case multiple sensors are used, mode-shapes can be used for structural identification. If only the fundamental frequency is known and the signal knowl- 


\begin{tabular}{|c|c|c|c|c|}
\hline & $\begin{array}{l}\text { Single-degree- } \\
\text { of-freedom model }\end{array}$ & $\begin{array}{l}\text { Multiple-degree- } \\
\text { of-freedom model }\end{array}$ & $\begin{array}{l}\text { Equivalent frame } \\
\text { model }\end{array}$ & $\begin{array}{l}\text { 3D finite/applied } \\
\text { element model }\end{array}$ \\
\hline $\begin{array}{l}\text { Model- } \\
\text { measurement } \\
\text { comparisons }\end{array}$ & $\begin{array}{l}\mathrm{f}_{\text {ini, } 1} \\
\mathrm{f}_{\text {peq, } 1} \\
\text { DG }\end{array}$ & $\begin{array}{c}\mathrm{f}_{\text {ini,i }} ; \varphi_{\text {ini,i }} \\
\mathrm{f}_{\text {peq }, \mathrm{i}} ; \varphi_{\text {peq }, \mathrm{i}} \\
\text { DG }\end{array}$ & $\begin{array}{l}\mathrm{f}_{\text {ini,i }} ; \varphi_{\text {ini,i }} \\
\mathrm{f}_{\text {peq,i }} ; \varphi_{\text {peq }, \mathrm{i}} \\
\quad(\mathrm{DG})\end{array}$ & $\begin{array}{c}\mathrm{f}_{\text {ini,i }} ; \varphi_{\text {ini,i }} \\
\mathrm{f}_{\text {peq,i }} ; \varphi_{\text {peq }, \mathrm{i}} \\
(\mathrm{DG})\end{array}$ \\
\hline $\begin{array}{l}\text { Damage } \\
\text { modelling }\end{array}$ & Global & $\begin{array}{l}\text { Lumped into } \\
\text { nonlinear springs }\end{array}$ & $\begin{array}{c}\text { Nonlinear springs / } \\
\text { nonlinear material } \\
\text { properties }\end{array}$ & $\begin{array}{l}\text { Nonlinear } \\
\text { material } \\
\text { properties }\end{array}$ \\
\hline $\begin{array}{l}\text { Number of } \\
\text { parameters }\end{array}$ & $4-6$ & $5-8$ & $6-12$ & $10->20$ \\
\hline Predictions & $\begin{array}{l}\text { Residual } \\
\text { capacity }\end{array}$ & $\begin{array}{l}\text { Residual } \\
\text { capacity }\end{array}$ & $\begin{array}{l}\text { Residual capacity } \\
\text { Approximate } \\
\text { retrofitting design }\end{array}$ & $\begin{array}{c}\text { Residual capacity } \\
\text { Retrofitting design } \\
\text { Failure modes }\end{array}$ \\
\hline $\begin{array}{c}\text { Model } \\
\text { simulations }\end{array}$ & $\begin{array}{l}\text { Dynamic } \\
\text { nonlinear }\end{array}$ & $\begin{array}{l}\text { Dynamic } \\
\text { nonlinear }\end{array}$ & $\begin{array}{c}\text { Dynamic or } \\
\text { static nonlinear }\end{array}$ & $\begin{array}{l}\text { Mostly static } \\
\text { nonlinear }\end{array}$ \\
\hline
\end{tabular}

Figure 4: Summary of typical model classes that are available for earthquake engineering with inherent properties related to model-measurement comparisons, damage modelling, number of parameters, and model predictions and simulations.

edge is good (due to a dense seismic network for instance), SDOF or MDOF models are preferred as they allow time-history analysis in a reasonable amount of time. If only the fundamental frequency is known and the signal knowledge is scarce, a model with higher model fidelity is needed to compensate the lack of information. For high-fidelity models, a good knowledge of the geometry is needed in order to limit the the uncertainty arising from parameters linked to geometry and material. If the building knowledge is scarce, two options are available to the engineer: iterate and increase the building information by on-site inspection or use simplified bi-linear behavior curves for static nonlinear predictions based on approximate building types. Such simplified and approximate analyses may be preferred for a rapid post-earthquake assessment at city-scale 
(such assessments fall outside the scope of this paper). When several modes are measured, as well as mode-shapes, behavior models with more degrees of freedom and higher fidelity are preferred as they allow the engineer to perform additional comparisons between model predictions and measurements.

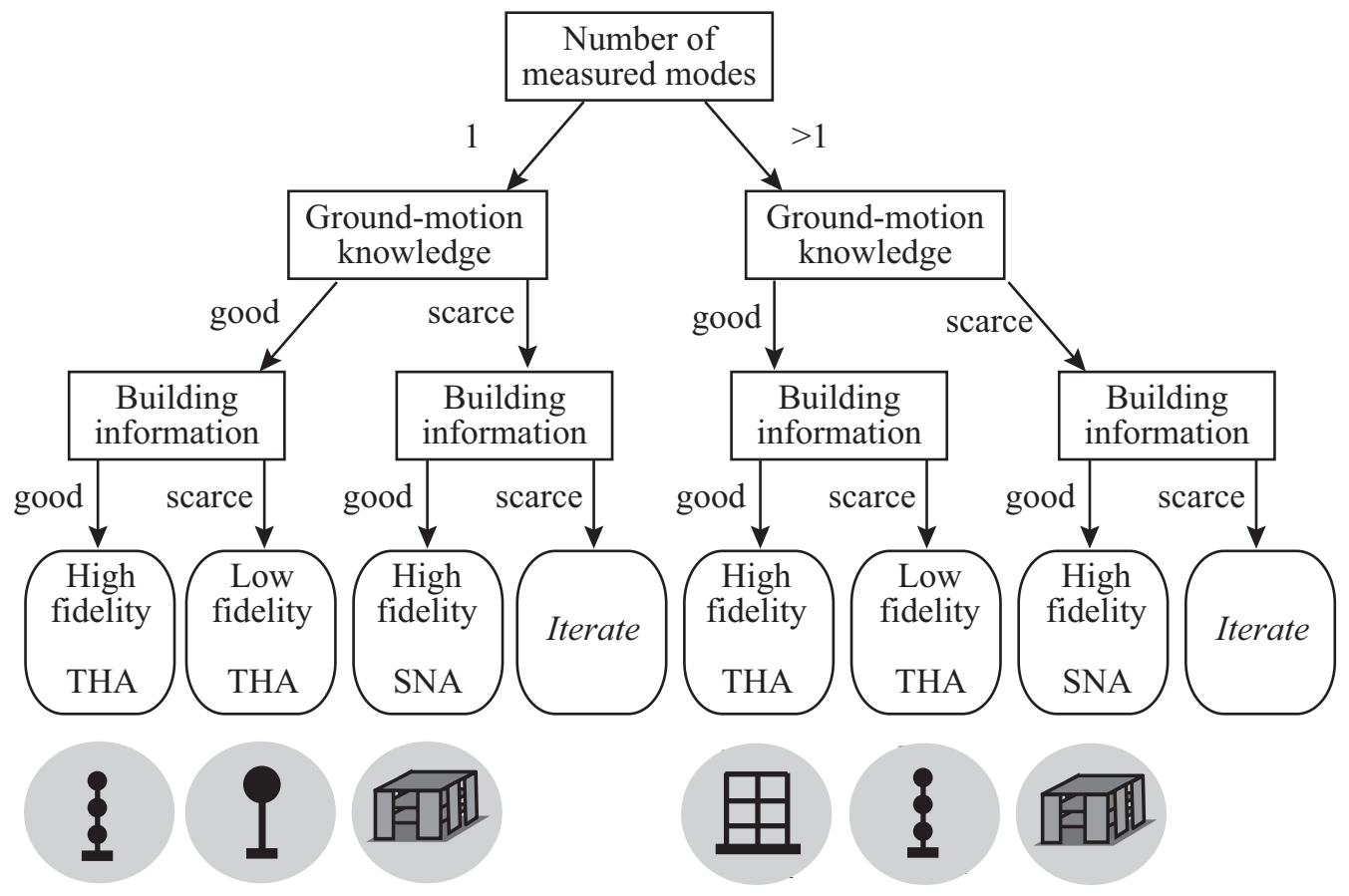

Figure 5: A-priori model-fidelity-class selection for post-earthquake assessment of buildings. In case of thorough post-earthquake analysis, building information can be gathered on site and should not be a limiting factor. For rapid post-earthquake assessment, low-fidelity models can be used as a first approach. Examples of potential model-fidelity classes are provided for each suggestion (see Figure 44. In the figure, THA refers to time-history analysis and SNA refers to static nonlinear analysis.

As can be observed from the proposed flowchart (Figure 5), the knowledge of ground motions mainly influences the type of analyses (either static or dynamic) rather than the model class. However, several combinations are excluded from the start, as in complete absence of building information and signal knowledge, uncertainties become excessive and hinder successful structural identification. In 
a similar way, time-history analyses involving high-fidelity models are generally too expensive from computational point of view. Due to excessive simulation time (in the order of several hours for time-history analysis of one model instance), AEM predictions are limited to pushover curves (static nonlinear predictions), and may only be applied in cases of good building-information knowledge.

The proposed model-class-selection approach can also be used in an iterative way. If either a first analysis with simplified models does not lead to clear results, or if building owners require in-depth analyses, additional information can be gathered to increase model fidelity and parameter identifiability. Therefore in cases with insufficient building information, several strategies can help to increase the knowledge regarding building information: site investigations; analyses based on SDOF models to explore the parameter space; taking additional measurement to determine the behavior type from modal properties (shear-type behavior or flexural behavior based on the mode shapes [75]). If a limited number of measurements hinders efficient data interpretation, supplementary measurements with multiple sensors can be performed, sometimes even laboratory tests on building material are performed (particularly in case multiple buildings of similar type exist within a residential district). Finally, all these criteria influence the global general behavior of the structure. If local failure modes need to be assessed, simplified SDOF models are not useful; more sophisticated models are needed.

\section{Case studies}

In order to apply the criteria for model-fidelity selection on earthquakedamaged buildings, two case studies are analyzed: a half-scale mixed masonryconcrete building tested on a shake-table and a masonry building measured in L'Aquila (Italy) after the damaging central-Italian earthquake in 2009. While shake-table tests allow comparison of identification results with observed behavior during subsequent tests (extrapolation), the L'Aquila building allows an evaluation of the model-fidelity selection and preliminary feature selection in real post-earthquake conditions. 


\subsection{Shake-table tests}

Although shake-table tests involve reduced levels of uncertainty (controlled uni-directional shaking, no environmental influences and few non-structural elements), measurements from shake-table tests performed by Beyer et al. [76]

A half-scale mixed un-reinforced-masonry reinforced-concrete building with four floors has been tested under an earthquake sequence with increasing shaking amplitudes. Schematic building drawings of the tested specimen are provided in Figure 6. To comply with similarity laws for stresses, additional masses component measured at the ground station of the Ulcinj-Hotel Albatros station during the April $15^{\text {th }}, 1979$ Montenegro earthquake [77] has been applied through the shake-table. This earthquake signal has a good fit with a slightly modified version of the Eurocode 8 spectrum for soil class D (see [76] for further details). shaking event. The maximum peak ground acceleration (PGA) that the structure has undergone prior to this building state is of $4 \mathrm{~m} \mathrm{~s}^{-2}$. The four subsequent shaking events are used to compare predictions (extrapolation) with observed behavior (that is not used for identification) and are characterized by PGA $6.3 \mathrm{~Hz}$ and $23.9 \mathrm{~Hz}$ are measured in the longitudinal direction during white-noise excitation following the fifth shaking event and are used for identification. A DG 2 is derived from visual inspection after the fifth shaking event [76].

\subsubsection{A-priori model-class selection}

To demonstrate a-priori selection of model classes, three scenarios involving changing data availability are compared (see Table 1). The first scenario, S1, involves scarce building information, good signal knowledge and the fundamental frequency together with the observed DG as measurement data. Therefore, based on the proposed a-priori model-fidelity selection (see Figure 5) a SDOF 
Elevation

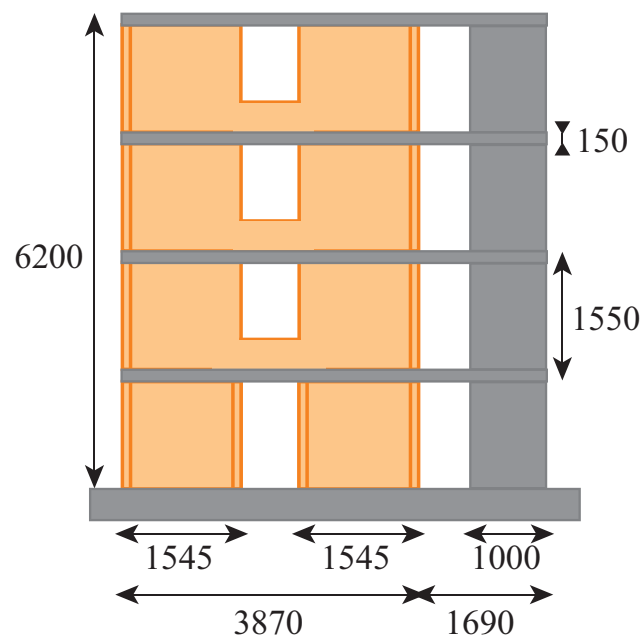

Top view

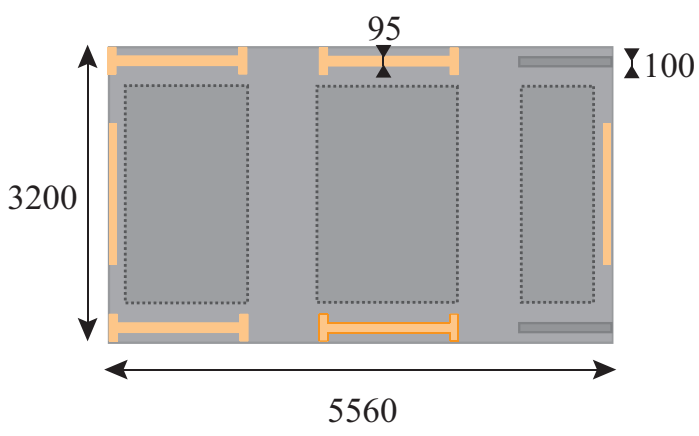

Reinforced concrete

Additional masses

Figure 6: Schematic drawings of the building structure tested on a shake table by [76. Dimensions are given in millimeters and correspond to a half-scale specimen. Additional masses have been added to comply with similarity laws for stresses. Shake-table tests have been uni-directional in the longitudinal direction.

the second scenario, S2 in Table 1, the same data is available to the engineer than in the first scenario, however two frequencies are measured (either from the start or in a second iteration). Thus, dynamic simulations of a MDOF model are performed to identify model instances. Finally, the third scenario involves detailed building information, absence of reliable signal knowledge and availability of the fundamental frequency only. Thus, an AEM model is selected. The scenarios and the respective data and model class are summarized in Table 1 and Figure 7 .

The SDOF model is based on an elastic-plastic hysteretic model with no 475 post-yield stiffness. As a result, only three parameters influence the dynamic behavior: initial (undamaged) frequency of the building, yield displacement and damping. Based on engineering judgment and experience from similar structures, 
Table 1: Three scenarios are tested for the shake-table case study based on availability of information for identification.

\begin{tabular}{cccccc}
\hline Scenario & Building inform. & Modes & Signal knowl. & Model & Analysis \\
\hline S1 & Scarce & 1 & Good & SDOF & Dynamic \\
S2 & Scarce & 2 & Good & MDOF & Dynamic \\
S3 & Detailed & 1 & Scarce & AEM & Static \\
\hline
\end{tabular}

(a) Scenario S1
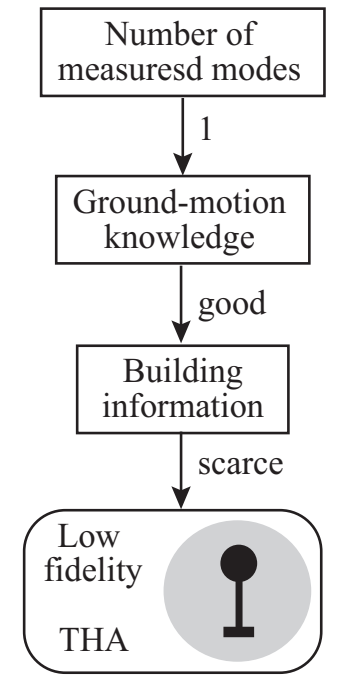

(b) Scenario S2
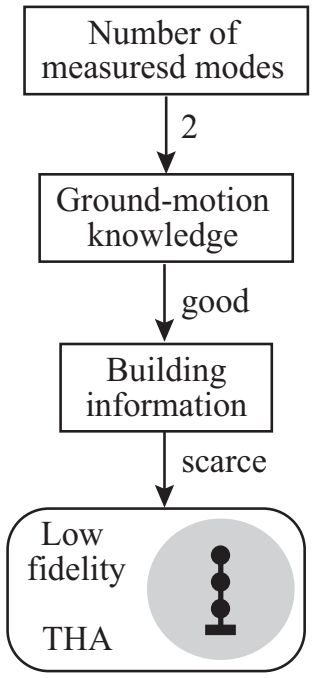

\section{(c) Scenario S3}
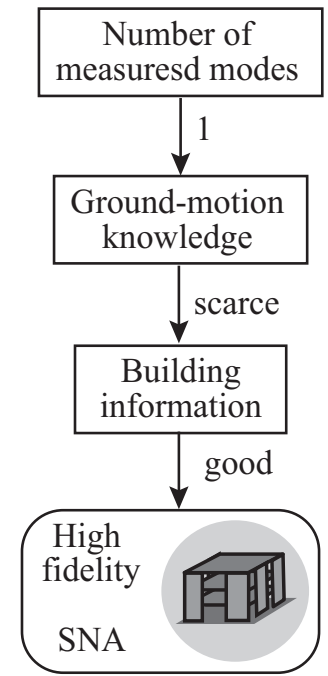

Figure 7: Model-class selection based on the proposed selection criteria (see 5 for the three analysed scenarios (see Table 1) of the shake-table case study.

initial intervals are selected for the parameters: From $4 \mathrm{~Hz}$ to $10 \mathrm{~Hz}$ for the undamaged frequency (13 divisions for grid sampling); from $1 \mathrm{~mm}$ to $31 \mathrm{~mm}$ for yield displacement (11 divisions); and from $2 \%$ to $8 \%$ for damping ( 5 divisions). The parameters and the related intervals and divisions are provided in Table 2 and result in an initial model population of 715 model instances.

The MDOF model involves a linear elastic lumped-mass model with a nonlinear hysteretic rotational spring at the base which lumps plasticity. The parameters that govern dynamic behavior of the MDOF model are: Bending 
stiffness (16 divisions from $1 \cdot 10^{10} \mathrm{~N} \mathrm{~m}^{2}$ to $6 \cdot 10^{10} \mathrm{~N} \mathrm{~m}^{2}$ ); story masses that are lumped at the slab level ( 5 divisions from 14 tons to 21 tons); viscous damping (3 divisions from $2 \%$ to $8 \%$ ); the stiffness of the rotational spring at the base of the cantilever beam ( 7 divisions from $10^{9.5} \mathrm{~N} \mathrm{~m} \mathrm{rad}^{-1}$ to $10^{11} \mathrm{~N} \mathrm{~m} \mathrm{rad}^{-1}$ ); and the yield rotation of the elastic perfectly-plastic rotational spring ( 7 divisions from $0.15 \mathrm{~km}^{-1}$ to $3 \mathrm{~km}^{-1}$. In total, 11760 initial model instances are simulated (see Table 2).

As the building is composed of several materials (un-reinforced masonry, reinforced concrete, reinforcement steel) and each material involves parameters that define nonlinear behavior (such as strength in tension and compression, ultimate strain, friction), the AEM model is defined by more than 30 parameters. Therefore, an initial sensitivity analysis is carried out to identify the parameters that have a influence exceeding five percent on average on initial frequency (linear prediction), yield displacement and frequency value related to $2 \mathrm{~mm}$ of top displacement (both nonlinear predictions). Retained parameters and their respective intervals are: Young's modulus of un-reinforced masonry (4 divisions from $2 \mathrm{kN} \mathrm{mm}^{-2}$ to $8 \mathrm{kN} \mathrm{mm}^{-2}$; tensile strength of un-reinforced masonry (4 divisions from $0.05 \mathrm{~N} \mathrm{~mm}^{-2}$ to $0.15 \mathrm{~N} \mathrm{~mm}^{-2}$ ); compression strength of un-reinforced masonry (2 divisions from $4 \mathrm{~N} \mathrm{~mm}^{-2}$ to $12 \mathrm{~N} \mathrm{~mm}^{-2}$; Young's modulus of reinforced concrete ( 3 divisions from $20 \mathrm{kN} \mathrm{mm}^{-2}$ to $40 \mathrm{kN} \mathrm{mm}^{-2}$ ); and tensile strength of reinforced concrete (2 divisions from $1 \mathrm{~N} \mathrm{~mm}^{-2}$ to $3 \mathrm{~N} \mathrm{~mm}^{-2}$ ). Thus, a total of 144 nonlinear static simulations are performed using AEM. An overview of the primary parameters (to identify) governing the three model classes and the selected parameter intervals are shown in Table 2 .

The combined uncertainties of estimated systematic model uncertainties and simulated secondary parameter uncertainties are: $[-50 \%, 20 \%]$ on natural frequencies and $[-50 \%, 80 \%]$ on displacements for the SDOF model (S1); $[-35 \%, 10 \%]$ on natural frequencies and $[-30 \%, 50 \%]$ on displacements for the MDOF model (S2); and $[-25 \%, 10 \%]$ on natural frequencies and $[-20 \%, 45 \%]$ on displacements for the 515 AEM model (S3). 
Table 2: Parameters chosen for identification related to the three selected model-fidelity classes and the respective ranges and number of divisions. Uniform distribution of parameters is assumed and no assumption regarding correlations between parameters is needed.

\begin{tabular}{ccccc}
\hline Model type & Parameter & Units & Interval & Divisions \\
\hline \multirow{2}{*}{ SDOF } & Initial freq. & $\mathrm{Hz}$ & {$[4,10]$} & 13 \\
& Yield disp. & $\mathrm{mm}$ & {$[1,21]$} & 11 \\
& Damping & $\%$ & {$[2,8]$} & 5 \\
\hline \multirow{2}{*}{ MDOF } & Bending stiff. & $\mathrm{Nm}^{2}$ & {$[1,6] \cdot 10^{1} 0$} & 16 \\
& Story mass & tons & {$[14,21]$} & 5 \\
& Damping & $\%$ & {$[2,8]$} & 3 \\
& Spring stiff. & $\log _{10}\left(\mathrm{Nmrad}^{-1}\right)$ & {$[9.5,11]$} & 7 \\
& Yield rotation & $10^{-} 3 \mathrm{rad}^{-2}$ & {$[0.15,3]$} & 7 \\
\hline \multirow{2}{*}{$\mathrm{AEM}$} & Young's mod. Mas. & $\mathrm{kNmm}^{-2}$ & {$[2,8]$} & 4 \\
& Tens. Strength Mas. & $\mathrm{Nmm}^{-2}$ & {$[0.05,1.5]$} & 3 \\
& Compr. Strength Mas. & $\mathrm{Nmm}^{-2}$ & {$[4,12]$} & 2 \\
& Young's mod. Concr. & $\mathrm{kNmm}^{-2}$ & {$[20,40]$} & 3 \\
& Tens. Strength Concr. & $\mathrm{Nmm}^{-2}$ & {$[1,3]$} & 2 \\
\hline
\end{tabular}

\subsubsection{Structural-identification results}

First, identification results involving scenario S1 (see Table 1) are analyzed. Using available data (DG and fundamental frequency), $74 \%$ of the initial model population are falsified. However, a more important criterion than the model predictions during the subsequent earthquake events that have been tested on the shake table (see section 4.1). The displacement-prediction range for the initial model population and the candidate model set are shown in Figure 8 . For the four earthquake events, the uncertainty of the prediction range is reduced

As discussed in sections 2.3 and 3 , knowledge of the earthquake signal has an important role in selecting the model-class fidelity and analysis type. Therefore, the same identification using SDOF model is performed without signal knowledge: 
15 historic earthquakes are randomly selected and scaled to $25 \%$ to $200 \%$ ( 7 divisions) of the true PGA of the damaging earthquake. While the falsification rate is similar ( $75 \%$ of the initial model population is falsified), the prediction uncertainty is comparable to the uncertainty of the initial model population that involves signal knowledge (see Figure 8). Thus, when time-history analyses are performed, the absence of precise knowledge of the earthquake signal hinders successful application of structural identification.

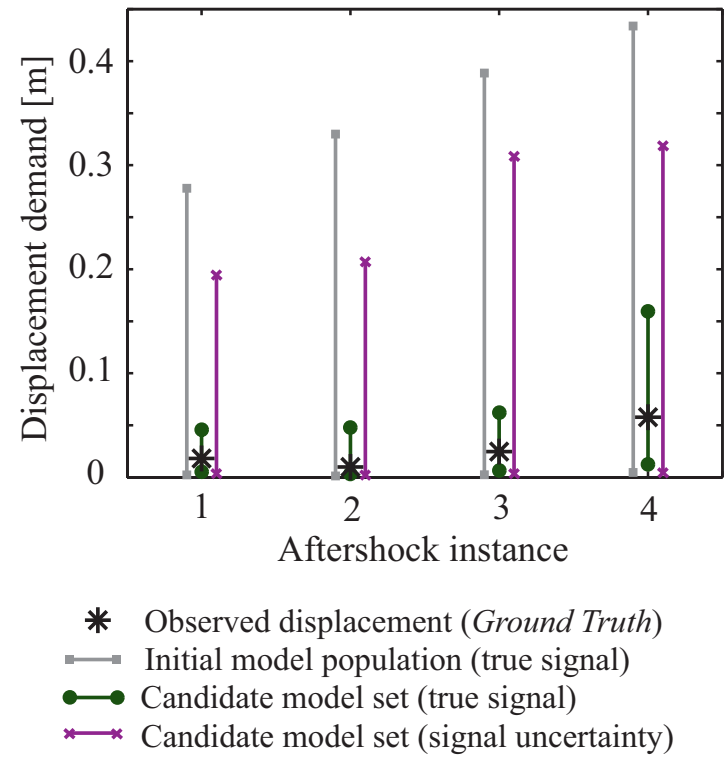

Figure 8: Displacement-demand prediction for subsequent aftershocks (not used for identification) based on SDOF models (Scenario S1 in Table 1 and Figure 7). Absence of signal knowledge undermines the advantage of structural identification. Predictions are made using the true signal of tested aftershocks.

As stated previously, $74 \%$ of the initial model population are falsified for scenario S1. For scenario S2 $97 \%$ of the initial model instances are falsified while $67 \%$ are falsified for scenario S3. Thus, static and dynamic approaches to post-earthquake model-based data interpretation provide significant reduction of ${ }_{540}$ the parametric uncertainty. In Figure 9, the displacement prediction uncertainty of the candidate models sets resulting from scenarios S1, S2 and S3 are compared. 
The vertical axis contains a much lower interval of values than Figure 8 , which underlines efficient reduction in parametric uncertainty for all three scenarios. In addition, the observed displacement is included in the prediction ranges for all scenarios and all subsequent earthquake events, which underlines the accuracy of the proposed post-earthquake structural-identification methodology as well as the applicability of proposed model-class selection criteria. The values of prediction precision changes with increasing levels of shaking, as can be seen in Figure 9. While SDOF and MDOF are more precise for low amplitudes, MDOF and AEM are more precise for higher amplitudes.

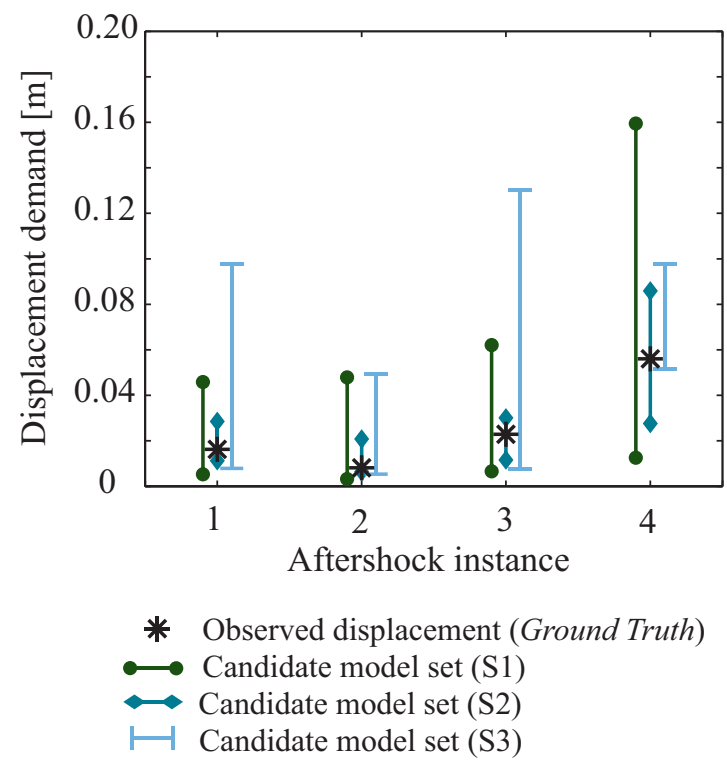

Figure 9: Displacement-demand prediction for subsequent aftershocks (information not used for identification) based on identification scenarios S1 to S3 (see Table 1 and Figure 7). All identification scenarios yield accurate prediction ranges. Simplified models (S1 and S2) provide precise results in case of good signal knowledge while detailed models (S3) compensate the absence of signal knowledge with enhanced building and material information.

When comparing the three model classes used in this examples, the computation times per model instance on a Intel(R) Xeon(R) CPU E5-2670 v3 @2.30GHz processor are: $1.6 \mathrm{~s}$ for the SDOF model (earthquake defined by 9000 
data points); $104 \mathrm{~s}$ for the MDOF model (earthquake defined by 36000 data

points); and 5300s for the AEM model (pushover curve based on 200 points). Computation time for dynamic analyses of the AEM model exceed 24 hours and thus, are considered non-practicable. These computation times are represented in Figure 10 a and are compatible with the schematic trend shown in the first graph of Figure 3

For the model classes corresponding to the three scenarios introduced in Table 1. simulation time, number of parameters as well as identification and prediction performances are summarized in Figure 10. Although the trends are based on only three points, they are in line with the tendencies shown in Figure 3. In this evaluation, the number of degrees of freedom is used as a proxy of model sophistication. Although it may not always be a representative value of model fidelity, it is deemed acceptable for the purpose of comparison between the three model classes. Given the significant growth in degrees of freedom from the SDOF model to the AEM model, log-scale representation is used. Prediction precision is taken as the probability related to the uniform prediction interval (inverse of the length of the prediction interval shown in Figure 9 for the four subsequent shaking events (named AS1, AS2, AS3 and AS4 in Figure 10-d). Secondary parameters (not identified) of the AEM model (see Figure 10-b) increase uncertainty bounds (in line with the schematic trend shown in the fourth graph of Figure 3) and thus, reduce identification performance. In this 575 application, the predictions based on the MDOF model provide highest precision (see 10 (c) and (d)). As schematically indicated in the fifth graph of Figure 3 . the most complex model class may not provide the best identification results (see Figure 10 c) and thus, not the most precise prediction of future behavior (see Figure 10-d). While this observation may not be universal and intermediate model classes between MDOF and AEM may provide even higher prediction, it underlines that simplified models should not be excluded from the start as they can provide useful information in post-earthquake assessment applications. 
(a)

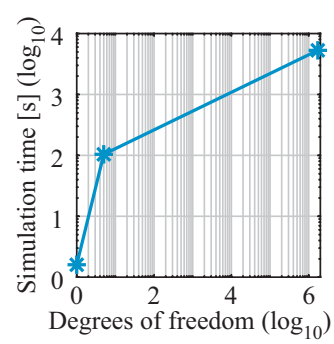

(b)

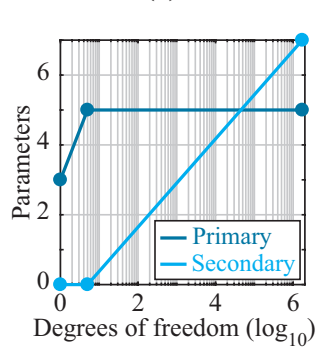

(c)

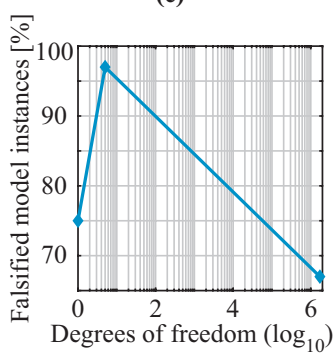

(d)

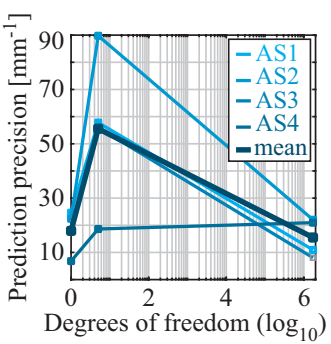

Figure 10: Comparison of the three model classes with respect to simulation time (a), number of parameters (b), falsification performance (c) and prediction precision (d). In graph (d), AS stands for aftershock. Precision is calculated for the 4 aftershocks that follow the investigated main shock, see Figure 9] Simulation time for the AEM model is related to static predictions, while simulation time of SDOF and MDOF model is related to dynamic predictions. Prediction precision is taken as the probability related to the uniform prediction interval. Limitations inherent to highly complex three-dimensional models (static predictions, no earthquake information) results in lower identification and prediction performances.

\subsection{Post-earthquake assessment of a building in L'Aquila, Italy}

The SS80-building in L'Aquila is a two-story masonry building with mixed class selection proposed in Section 3 (see Figure 5), pushover curves derived using AEM are used to define the residual capacity of the SS80 building in 
L'Aquila.

600

\subsubsection{Structural model}

In a similar way to Scenario S3 in Figure 7 model-class selection criteria lead to the selection of a high-fidelity model based on the AEM method. By counting the two masonry types, concrete elements (slabs), reinforcement steel and the roof structure, the number of parameters exceeds 50. The number of simulation runs that is required to establish the sensitivity of predicted values with respect to all material parameters would be prohibitive (for instance, 4901 model instances would be required for a sensitivity analysis based on a BoxBehnken design of experiments). Therefore, engineering reasoning is used to obtain an initial reduction in the number of parameters. Same mortar quality for all types of bricks is assumed. Also, assuming separation strain and friction coefficient are governed by mortar properties, identical values are taken for both masonry types. An equivalent slab is used instead of a precise representation of the slab element. As pushover curves are simulated, a rigid-diaphragm behavior of the slab is assumed. In addition, failure is estimated to occur in the masonry parts, thus non-linearity of other elements are not taken into account. Fixed boundary conditions are assumed (no information on the soil and the type of foundation is available). Finally, non-structural elements that contribute to the mass are modelled as unknown distributed mass.

As a result, ten parameters are kept for an initial sensitivity analysis: (i) additional mass on the first floor $\left(0 \mathrm{~kg} \mathrm{~m}^{-2}\right.$ to $200 \mathrm{~kg} \mathrm{~m}^{-2}$; (ii) Young's modulus of the bricks of the lower story $\left(6 \mathrm{kN} \mathrm{mm}^{-2}\right.$ to $\left.14 \mathrm{kN} \mathrm{mm}^{-2}\right)$; (iii) compression strength of the bricks of the lower story $\left(10 \mathrm{~N} \mathrm{~mm}^{-2}\right.$ to $\left.25 \mathrm{~N} \mathrm{~mm}^{-2}\right)$; (iv) tensile strength of the bricks of the lower floor $\left(0.5 \mathrm{~N} \mathrm{~mm}^{-2}\right.$ to $\left.2.5 \mathrm{~N} \mathrm{~mm}^{-2}\right) ;(v)$ Young's modulus of the bricks of the upper story $\left(3 \mathrm{~N} \mathrm{~mm}^{-2}\right.$ to $\left.10 \mathrm{~N} \mathrm{~mm}^{-2}\right)$; (vi) compression strength of the bricks of the upper story $\left(5 \mathrm{~N} \mathrm{~mm}^{-2}\right.$ to $\left.18 \mathrm{~N} \mathrm{~mm}^{-2}\right)$; (vii) tensile strength of the bricks of the upper story $\left(0.25 \mathrm{~N} \mathrm{~mm}^{-2}\right.$ to $\left.2 \mathrm{~N} \mathrm{~mm}^{-2}\right)$; (viii) separation strain of all masonry elements (0.05 to 0.20); (ix) friction value of all masonry values (0.6 to 0.9 ); and ( $x$ ) wall thickness $(24 \mathrm{~cm}$ to $45 \mathrm{~cm})$. 
Lack of detailed information in the building plans is reflected by large uncertainty in wall thickness. As it is not clear from the drawings whether the thickness includes cladding, the range of values is taken in a conservative way from $24 \mathrm{~cm}$, which is the depth of the bricks that have been used for the building, up to $45 \mathrm{~cm}$, which is the dimension indicated in the drawings. Initial modal simulations indicate that a wall thickness of $45 \mathrm{~cm}$ is incompatible with measured post-earthquake frequencies. Therefore, the wall thickness is set to $24 \mathrm{~cm}$. A Box-Behnken scheme is used to sample the parameter space defined by the remaining nine parameters.

The sensitivity of the model predictions with respect to these nine parameters is calculated using linear regression and is reported in Table 3 . Relative importance of Young's moduli is higher than relative importance of all the other parameters on the mostly linear predictions (frequencies and yield displacement). The relative importance of compressive and tensile strength of the masonry of the lower story (referred to as masonry 1) is higher than for the masonry parameters of the second story. Ultimate displacement capacity shows highest sensitivity to the separation strain of masonry.

\subsubsection{Structural identification with little measurement information}

The AEM model is used to predict pushover curves and the frequency drop that is due to top displacements, based on three chosen primary parameters (Young's moduli of the two masonry types and separation strain). The following uncertainties affect displacement and frequency intervals for identification:

- Stiff boundary conditions without soil-structure interaction are assumed, thus an uncertainty range of $[-10 \%, 0]$ is estimated for frequency predictions and an uncertainty range of $[0,15 \%]$ for displacement predictions.

- As unloading is not simulated by the means of a pushover analysis, the fundamental frequency that is related to a given top displacement may be underestimated by a maximum of $15 \%$.

- Measurement uncertainty that arises for natural frequencies derived from 
Table 3: Sensitivity of linear (initial frequency) and nonlinear (frequency related to a top displacement of $4 \mathrm{~mm}$, yield displacement and ultimate displacement) model predictions with respect to the chosen material properties. The three parameters that are chosen for identification are the two Young's moduli and the separation strain of mortar.

\begin{tabular}{lcccc}
\hline Parameter & \multicolumn{4}{c}{ Relative importance } \\
& Init. freq. & Freq. 4mm & Yield disp. & Ult. disp. \\
\hline Young's mod. mas. 1 & 0.42 & 0.23 & -0.65 & -0.04 \\
Young's mod. mas. 2 & 0.54 & 0.39 & -0.02 & -0.10 \\
Compr. strength mas. 1 & 0.00 & 0.08 & 0.11 & -0.05 \\
Compr. strength mas. 2 & 0.01 & 0.06 & 0.01 & -0.04 \\
Tensile strength mas. 1 & 0.00 & 0.09 & 0.15 & 0.10 \\
Tensile strength mas. 2 & 0.00 & 0.10 & -0.03 & 0.10 \\
Friction coefficient & 0.00 & -0.02 & -0.02 & -0.05 \\
Separation strain & 0.00 & 0.03 & -0.01 & 0.49 \\
Additional mass & -0.02 & -0.01 & 0.00 & 0.04 \\
\hline
\end{tabular}

ambient-vibration measurements is considered to follow a zero-mean Gaussian distribution having a standard deviation of $0.5 \mathrm{~Hz}$.

- As for the previous case study, the threshold bounds that are delimiting the displacement values that are compatible with a DG of 2 are considered to be $\left[0.5 \cdot D_{y}, 2.0 \cdot D_{y}\right]$.

Model predictions for frequency drops related to top displacements as well as pushover curves are shown in Figure 11. The displacement ranges that are compatible with the measured frequency and the observed DG 2 are highlighted. Candidate models have an overlapping of the displacement intervals related to both conditions (see equation ?? in Section 2.4.

Using only post-earthquake frequency and the observed DG, $31 \%$ of the parameter combinations of the initial model population are falsified. The candidate 670 parameter combinations are reported in a parallel axes plot in Figure 12 Parameter combinations with high values of Young's moduli for both masonry types 

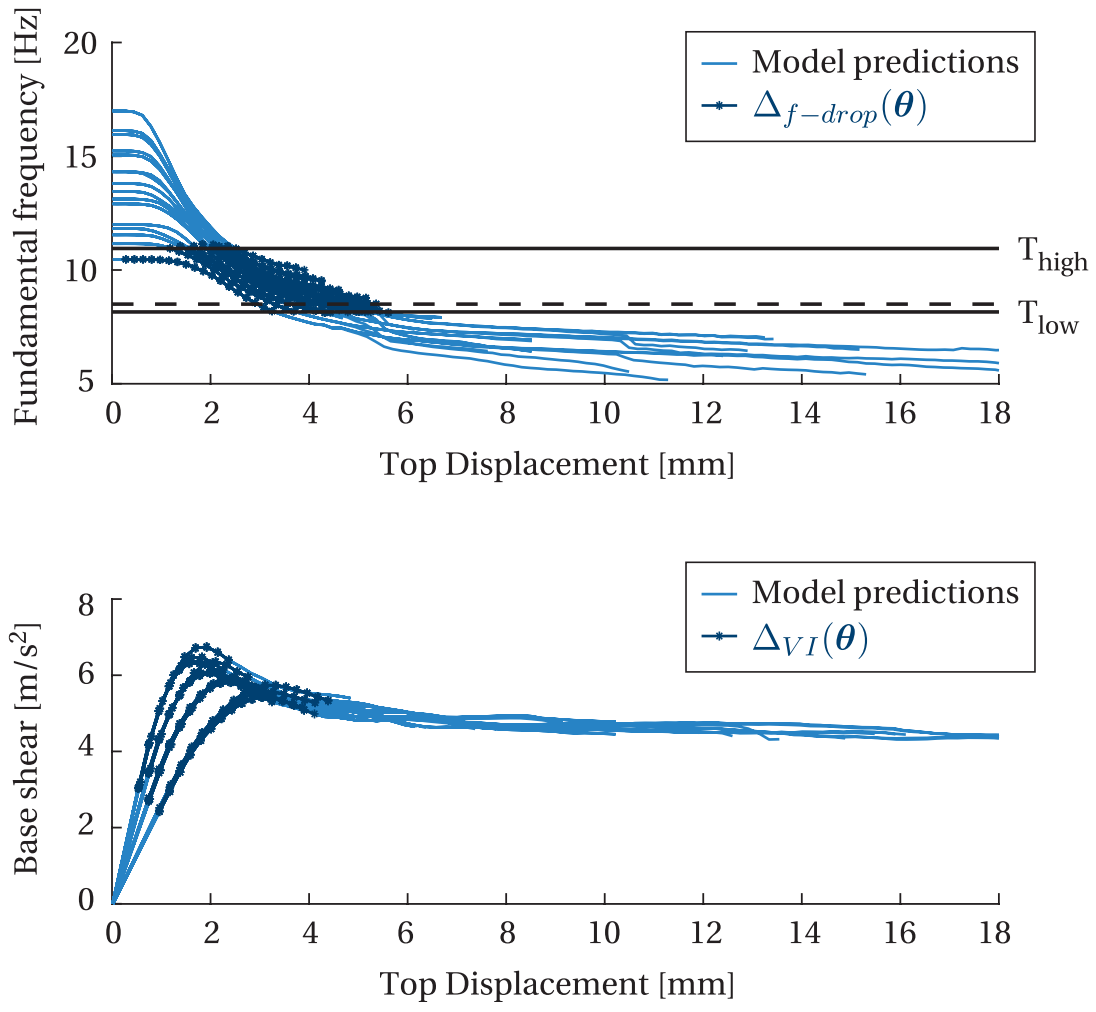

Figure 11: Predictions of frequency drops (top figure) and shear forces at the base of the building (bottom figure) that correspond to increasing top displacements. Candidate models, which verify Eq. ??, are highlighted. It is recalled that no earthquake-signal knowledge is required for Eq. ??.

are falsified. However, no reduction in parameter ranges is obtained. In addition, as structural identification is based on pushover curves, a subsequent iteration is mandatory, as experienced engineers verify that out-of-plane and brittle failure mechanisms can be excluded. In case of this slightly cracked building with only two storeys and with stiff floors, such out-of-plane mechanisms can generally be excluded.

In order to simplify nonlinear static predictions, a response spectrum from the Italian building code (Italian annex to the Eurocode) is used. Using the spectrum for L'Aquila that is defined to have a probability of exceedance of 


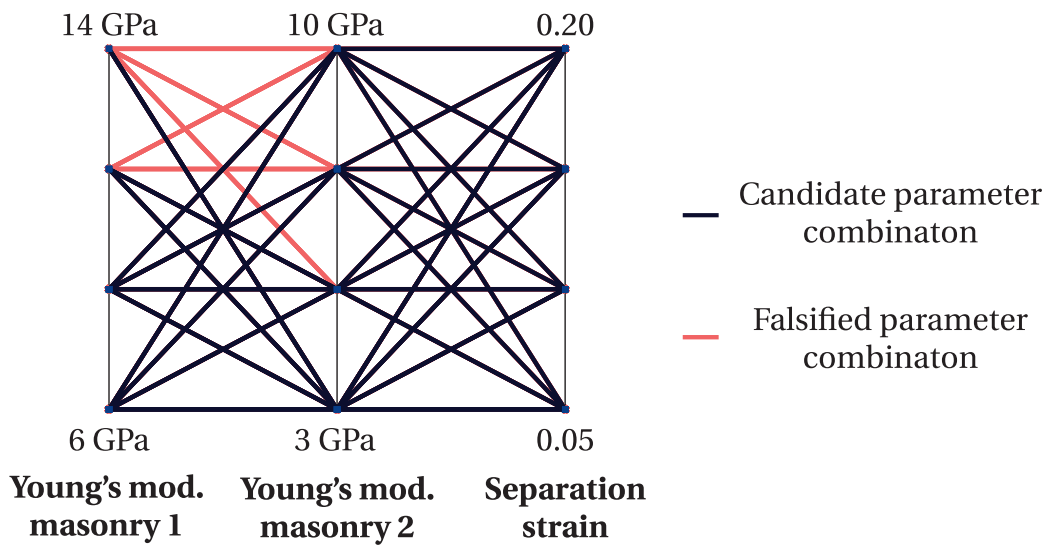

Figure 12: Identified parameter combinations for the SS80 building in L'Aquila based on post-earthquake information only. $31 \%$ of the model population are falsified.

10\% in 50 years, high DGs are predicted ( $\geq 3$ ): $23 \%$ probability of a DG3, $35 \%$ probability of a DG4 and $45 \%$ probability of a DG5.

In absence of information regarding the ground-motion signals and without data related to the initial state of the building, combining post-earthquake frequency and observed DGs can be an efficient starting point. Using highfidelity three-dimensional models, the number of parameter combinations that are compatible with post-earthquake frequencies and observed DGs can be reduced. In addition, it should be noted that due to the excessive computation time and high number of parameters engineering experience is required to perform an initial reduction in the number of to reduce the number of parameters to be identified.

\section{Discussion}

An a-priori selection of model fidelity for measurement-supported postearthquake assessment is proposed and applied to two case studies. Several analyses types are proposed and compared. However, several limitations are notable with respect to SDOF simulations as well as static nonlinear simulations. Such analyses types and models are usually limited to specific failure modes 
(i.e. gradual in-plane failure mechanisms). Therefore, the engineer needs to verify the validity of such assumptions (for instance presence of stiff floors in masonry buildings to ensure load distributions between vertical elements and reduce likelihood of out-of-plane failure modes).

The approach to model-class selection described in this paper is limited to criteria that help engineers select an appropriate model fidelity.. Selection of appropriate model classes with similar model fidelity (i.e. feature selection or selection of model classes with similar fidelity, such as flexural, shear or combined MDOF models) falls outside the scope of this paper and is part of future work. In addition, measurements used in this paper are limited to post-earthquake measurements. Implementation of time-history measurements are not included as well as extrapolation of assessment to city-scale levels, although there is much potential for city-scale studies.

\section{Conclusions}

Multiple model classes and analysis types are available in earthquake engineering. Competing factors, such as computation time, parameter identifiability and level of uncertainties, undermine development of universal selection criteria that would favor a given model class for all post-earthquake-assessment applications. Therefore, this paper contains a proposal for a-priori model-class selection for post-earthquake assessment using model-based data interpretation. Natural frequencies (derived from ambient-vibration measurements after the mainshock) and visual damage inspection are assumed to be available; continuously monitored buildings are not covered in this paper. The following conclusions are drawn:

- Factors that are identified to have the most influence on the choice of optimal model class and analysis type are: knowledge of the accelerogram of the damaging earthquake, information regarding building geometry and material types as well as the amount of reliable modal properties that can 
be deduced from measurement data. This has led to a flowchart for a-priori model-class selection based on these parameters.

- Taking vibration measurements and interpreting them using a population of physics-based models is useful for structural assessment in all cases.

\section{Acknowledgements}

The authors acknowledge Earthquake Engineering and Structural Dynamics Laboratory, EPFL, for providing the test results. This work was funded by the 
Swiss National Science Foundation under Contract No. 200020-169026.

\section{References}

[1] N. Nazari, J. Van de Lindt, Y. Li, Quantifying changes in structural design needed to account for aftershock hazard, Journal of Structural Engineering 141 (11) (2015) 04015035.

[2] C. Baggio, A. Bernardini, R. Colozza, L. Corazza, M. Della Bella, G. Di Pasquale, M. Dolce, A. Goretti, A. Martinelli, G. Orsini, others, Field manual for post-earthquake damage and safety assessment and short term countermeasures (AeDES), JRC Scientific and Technical Reports.

[3] T. Rossetto, A. Kappos, L. Kouris, M. Indirli, R. Borg, T. Lloyd, V. SwordDaniels, Comparison of damage assessment methodologies for different natural hazards, Urban habitat constructions under catastrophic events (Proceedings).

[4] B. Galloway, J. Hare, D. Brunsdon, P. Wood, B. Lizundia, M. Stannard, Lessons from the Post-Earthquake Evaluation of Damaged Buildings in Christchurch, Earthquake Spectra 30 (1) (2014) 451-474.

[5] S.-L. Lin, S. Uma, A. King, Empirical Fragility Curves for Non-Residential Buildings from the 2010-2011 Canterbury Earthquake Sequence, Journal of Earthquake Engineering (2017) 1-29.

[6] J. D. Marshall, K. Jaiswal, N. Gould, F. Turner, B. Lizundia, J. C. Barnes, Post-Earthquake Building Safety Inspection: Lessons from the Canterbury, New Zealand, Earthquakes, Earthquake Spectra 29 (3) (2013) 1091-1107.

[7] D. A. McEntire, J. Cope, Damage Assessment After the Paso Robles, San Simeon, California, Earthquake: Lessons for Emergency Management, Natural Hazards Center, 2004. 
[8] F. Marquis, J. J. Kim, K. J. Elwood, S. E. Chang, Understanding postearthquake decisions on multi-storey concrete buildings in Christchurch, New Zealand, Bulletin of Earthquake Engineering 15 (2) (2017) 731-758.

[9] L. Wade, Cheap devices bring quake damage sensing to the masses, Science 363 (6430) (2019) 912-913. doi:10.1126/science.363.6430.912

[10] F. Jalayer, D. Asprone, A. Prota, G. Manfredi, A decision support system

[15] M. Celebi, A. Sanli, M. Sinclair, S. Gallant, D. Radulescu, Real-time seismic monitoring needs of a building ownerand the solution: a cooperative effort, Earthquake Spectra 20 (2) (2004) 333-346.

[16] M. Picozzi, R. Ditommaso, S. Parolai, M. Mucciarelli, C. Milkereit, M. Sofor post-earthquake reliability assessment of structures subjected to aftershocks: an application to LAquila earthquake, 2009, Bulletin of Earthquake Engineering 9 (4) (2011) 997-1014.

[11] J.-A. Goulet, C. Michel, A. D. Kiureghian, Data-driven post-earthquake rapid structural safety assessment, Earthquake Engineering \& Structural Dynamics 44 (4) (2015) 549-562.

[12] E. M. Hernandez, G. May, Post-earthquake damage detection in instrumented buildings using identified dissipated energy, in: Topics in Modal Analysis II, Volume 6, Springer, 2012, pp. 351-358.

[13] F. Naeim, S. Hagie, A. Alimoradi, E. Miranda, Automated post-earthquake damage assessment of instrumented buildings, Advances in Earthquake Engineering for Urban Risk Reduction (2006) 117-134.

[14] F. Naeim, H. Lee, S. Hagie, H. Bhatia, A. Alimoradi, E. Miranda, Three-dimensional analysis, real-time visualization, and automated postearthquake damage assessment of buildings, The Structural Design of Tall and Special Buildings 15 (1) (2006) 105-138.

biesiak, D. Di Giacomo, M. Gallipoli, M. Pilz, M. Vona, others, Real time 
monitoring of structures in task force missions: the example of the $\mathrm{Mw}=$ 6.3 Central Italy Earthquake, April 6, 2009, Natural Hazards 52 (2) (2010) $253-256$.

[17] A. Réveillère, P. Gehl, D. Seyedi, H. Modaressi, Development of seismic fragility curves for mainshock-damaged reinforced-concrete structures, 2012, p. 999.

[18] J.-S. Jeon, R. DesRoches, L. N. Lowes, I. Brilakis, Framework of aftershock fragility assessment-case studies: older california reinforced concrete building frames, Earthquake Engineering \& Structural Dynamics 44 (15) (2015) $2617-2636$.

[19] M. Raghunandan, A. B. Liel, N. Luco, Aftershock collapse vulnerability assessment of reinforced concrete frame structures, Earthquake Engineering \& Structural Dynamics 44 (3) (2015) 419-439.

[20] P. Mouroux, B. L. Brun, Presentation of RISK-UE project, Bulletin of Earthquake Engineering 4 (4) (2006) 323-339.

[21] P. Lestuzzi, S. Podestà, C. Luchini, A. Garofano, D. Kazantzidou-Firtinidou, C. Bozzano, Validation and improvement of Risk-UE LM2 capacity curves for URM buildings with stiff floors and RC shear walls buildings, Bulletin of Earthquake Engineering (2016) 1-24.

[22] F. Lanata, A. Del Grosso, Damage detection and localization for continuous static monitoring of structures using a proper orthogonal decomposition of signals, Smart materials and structures 15 (6) (2006) 1811.

[23] H. Wang, A.-q. Li, J. Li, Progressive finite element model calibration of a long-span suspension bridge based on ambient vibration and static measurements, Engineering Structures 32 (9) (2010) 2546-2556.

[24] A. Strauss, R. Wendner, D. M. Frangopol, K. Bergmeister, Influence linemodel correction approach for the assessment of engineering structures using 
novel monitoring techniques, Smart Structures and Systems 9 (1) (2012) $1-20$.

835

[33] S. G. S. Pai, A. Nussbaumer, I. F. C. Smith, Comparing structural identification methodologies for fatigue life prediction of a highway bridge, Frontiers in Built Environment 3 (2018) 73. 
[34] M. Song, I. Behmanesh, B. Moaveni, C. Papadimitriou, Modeling error estimation and response prediction of a 10-story building model through a hierarchical bayesian model updating framework, Frontiers in Built Environment 5 (2019) 7.

[35] I. F. Smith, S. G. S. Pai, A practical engineering approach to interpreting measurement data in uncertain contexts, in: International Conference on Sustainable Infrastructure, 2017, p. 26.

[36] K.-V. Yuen, Recent developments of bayesian model class selection and applications in civil engineering, Structural Safety 32 (5) (2010) 338-346.

[37] M. Muto, J. L. Beck, Bayesian updating and model class selection for hysteretic structural models using stochastic simulation, Journal of Vibration and Control 14 (1-2) (2008) 7-34.

[38] J. Ching, M. Muto, J. L. Beck, Structural model updating and health monitoring with incomplete modal data using Gibbs sampler, Comput. Aided Civ. Infrastruct. Eng. 21 (2006) 242.

[39] S. H. Cheung, J. L. Beck, Calculation of posterior probabilities for Bayesian model class assessment and averaging from posterior samples based on dynamic system data, Computer-Aided Civil and Infrastructure Engineering 25 (5) (2010) 304-321.

[40] I. Behmanesh, B. Moaveni, Probabilistic identification of simulated damage on the dowling hall footbridge through bayesian finite element model updating, Structural Control and Health Monitoring 22 (3) (2015) 463-483.

[41] K. L. Van Buren, S. Atamturktur, F. M. Hemez, Model selection through robustness and fidelity criteria: modeling the dynamics of the cx-100 wind turbine blade, Mechanical Systems and Signal Processing 43 (1-2) (2014) 246-259. 
[42] J.-A. Goulet, P. Kripakaran, I. F. C. Smith, Multimodel structural performance monitoring, Journal of Structural Engineering 136 (10) (2010) 1309-1318.

[43] I. F. Smith, Studies of Sensor-Data Interpretation for Asset Management of the Built Environment, Frontiers in Built Environment 2 (2016) 8.

[44] Z. Šidák, Rectangular confidence regions for the means of multivariate normal distributions, Journal of the American Statistical Association 62 (318) (1967) 626-633.

[45] R. Pasquier, Performance assessment and prognosis for civil infrastructure based on model falsification reasoning EPFL thesis number 6756 (184 pages).

[46] Y. Belmouden, P. Lestuzzi, An equivalent frame model for seismic analysis of masonry and reinforced concrete buildings, Construction and Building Materials 23 (1) (2009) 40-53.

[47] P. Roca, M. Cervera, G. Gariup, L. Pela, Structural analysis of masonry historical constructions. classical and advanced approaches, Archives of Computational Methods in Engineering 17 (3) (2010) 299-325.

[48] S. Lagomarsino, A. Penna, A. Galasco, S. Cattari, Tremuri program: an equivalent frame model for the nonlinear seismic analysis of masonry buildings, Engineering Structures 56 (2013) 1787-1799.

[49] K. Meguro, H. S. Tagel-Din, Applied element method used for large displacement structural analysis, Journal of Natural Disaster Science 24 (1) (2002) 25-34.

[50] H. Okamura, K. Maekawa, Nonlinear analysis and constitutive models of reinforced concrete, Gihodo, Tokyo 10.

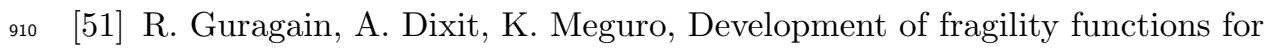
low strength masonry buildings in Nepal using applied element methods, in: 15th world conference of earthquake engineering, Lisbon, Portugal, 2012. 
[52] A. Karbassi, M.-J. Nollet, Performance-Based Seismic Vulnerability Evaluation of Masonry Buildings Using Applied Element Method in a Nonlinear Dynamic-Based Analytical Procedure, Earthquake Spectra 29 (2) (2013) 399-426.

[53] A. Garofano, P. Lestuzzi, Seismic Assessment of a Historical Masonry Building in Switzerland: The Ancien Hôpital De Sion, International Journal of Architectural Heritage 10 (8) (2016) 975-992.

[54] L. Diana, Y. Reuland, P. Lestuzzi, Seismic vulnerability assessment of sion cathedral(switzerland): an integrated approach to detect and evaluate local collapse mechanisms in heritage buildings, in: Prohitech" 17: 3rd international conference on protection of historical constructions, 2017.

[55] Y. Reuland, L. Diana, L. Lestuzzi, I. Smith, Structural resilience through model-based data interpretation: From building to city-scale post-seismic assessment, in: S. Research Publishing (Ed.), Proceedings of the 6th International Symposium on Reliability and Risk Management Singapore (6ISRERM), 2018, pp. 543-548.

[56] C. Michel, B. Zapico, P. Lestuzzi, F. J. Molina, F. Weber, Quantification of fundamental frequency drop for unreinforced masonry buildings from dynamic tests, Earthquake Engineering \& Structural Dynamics 40 (11) (2011) 1283-1296.

[57] G. Calvi, R. Pinho, G. Magenes, J. Bommer, L. Restrepo-Velez, H. Crowley, Development of seismic vulnerability assessment methodologies over the past 30 years, ISET journal of Earthquake Technology 43 (3) (2006) 75-104.

[58] N. M. Newmark, W. J. Hall, Seismic design criteria for nuclear reactor facilities, in: Proceedings of the 4th World conference on Earthquake Engineering, Vol. 4, 1969, pp. 37-50.

[59] E. Miranda, V. V. Bertero, Evaluation of seismic performance of a ten-story 
rc building during the whittier narrows earthquake, Vol. 91, Earthquake Engineering Research Center, University of California, 1991.

[60] S. Cattari, S. Lagomarsino, Seismic assessment of mixed masonry-reinforced concrete buildings by non-linear static analyses, Earthq Struct 4 (3) (2013) $241-264$.

[61] Y.-Y. Lin, E. Miranda, Noniterative equivalent linear method for evaluation of existing structures, Journal of structural engineering 134 (11) (2008) 1685-1695.

[62] P. Fajfar, P. Gašperšič, The $\mathrm{n} 2$ method for the seismic damage analysis of rc buildings, Earthquake Engineering \& Structural Dynamics 25 (1) (1996) $31-46$.

[63] P. Fajfar, A nonlinear analysis method for performance-based seismic design, Earthquake spectra 16 (3) (2000) 573-592.

[64] A. VELETSOS, Effect of inelastic behavior on the response of simple systems to earthquake motion, in: Proc. of 2nd World Conference on Earthquake Engineering, 1960, pp. 895-912.

[65] C. Michel, P. Lestuzzi, C. Lacave, Simplified non-linear seismic displacement demand prediction for low period structures, Bulletin of earthquake engineering 12 (4) (2014) 1563-1581.

[66] L. Diana, A. Manno, P. Lestuzzi, S. Podestà, C. Luchini, Impact of displacement demand reliability for seismic vulnerability assessment at an urban scale, Soil Dynamics and Earthquake Engineering 112 (2018) 35-52.

[67] S. Antoniou, A. Rovithakis, R. Pinho, Development and verification of a fully adaptive pushover procedure, in: Proceedings of the Twelfth European Conference on Earthquake Engineering, 2002.

965 [68] S. Antoniou, R. Pinho, Advantages and limitations of adaptive and nonadaptive force-based pushover procedures, Journal of Earthquake Engineering 8 (04) (2004) 497-522. 
[69] G. Grünthal, R. M. V. Musson, J. Schwarz, M. Stucchi, European Macroseismic Scale 1998, EMS-98. Cahiers du Centre Européen de Géodynamique et de Séismologie, Volume 19. (2001).

[70] G. M. Calvi, R. Pinho, H. Crowley, State-of-the-knowledge on the period elongation of RC buildings during strong ground shaking, in: PROC (CD) First European Conference on Earthquake Engineering and seismology, Geneva, Switzerland, 2006, pp. 3-8.

[71] S. Lagomarsino, S. Giovinazzi, Macroseismic and mechanical models for the vulnerability and damage assessment of current buildings, Bulletin of Earthquake Engineering 4 (4) (2006) 415-443.

[72] Y. Reuland, P. Lestuzzi, I. F. C. Smith, Measurement-based support for post-earthquake assessment of buildings, Structure and Infrastructure Engineering 0 (0) (2019) 1-16. doi:10.1080/15732479.2019.1569071.

[73] Y. Reuland, P. Lestuzzi, I. F. Smith, A model-based data-interpretation framework for post-earthquake building assessment with scarce measurement data, Soil Dynamics and Earthquake Engineering 116 (2019) 253-263.

[74] T. Takeda, M. A. Sozen, N. N. Nielsen, Reinforced concrete response to simulated earthquakes, Journal of the Structural Division 96 (12) (1970) $2557-2573$.

[75] Y. Reuland, A. Garofano, P. Lestuzzi, I. F. Smith, Evaluating seismic retrofitting efficiency through ambient vibration tests and analytical models, in: IABSE Symposium Report, Vol. 105, International Association for Bridge and Structural Engineering, 2015, pp. 1-8.

[76] K. Beyer, M. Tondelli, S. Petry, S. Peloso, Dynamic testing of a fourstorey building with reinforced concrete and unreinforced masonry walls: prediction, test results and data set, Bulletin of Earthquake Engineering 13 (10) (2015) 3015-3064. 
[77] N. Ambraseys, P. Smit, J. Douglas, B. Margaris, R. Sigbjrnsson, S. Olafsson, P. Suhadolc, G. Costa, Internet site for European strong-motion data, Bollettino di Geofisica Teorica ed Applicata 45 (3) (2004) 113-129.

[78] C. Michel, M. Oropeza, Post-earthquake survey in L'Aquila (Italy) - Ambient vibration experiment report., Tech. rep., Ecole Polytechnique Fédérale de Lausanne, Applied Computing and Mechanics Laboratory (EPFL-IMAC), Lausanne, Switzerland (2009).

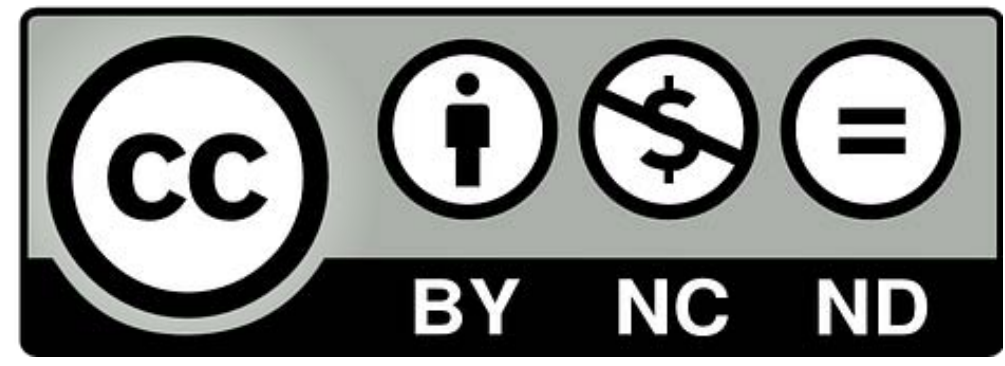

